\title{
INTENTOS DE RENOVACIÓN DE ALGUNAS DISCIPLINAS EXPERIMENTALES EN LA FACULTAD DE MEDICINA DE SANTIAGO: LOS CURSOS DE PAUL HOFFMANN (1923 Y 1924), AMÉDÉE GUY (1928) Y EDUARD REICHENOW (1935)*
}

\author{
Guillermo Olagüe de Ros \\ Universidad de Granada \\ Fernando J. Ponte Hernando \\ Universidad de Santiago de Compostela**
}

\begin{abstract}
* Este trabajo se ha realizado con cargo al Programa de Fortalecimiento de las Capacidades I+D+I, Ayudas para el Mantenimiento de la Actividad de los Grupos de Investigación (Grupo de Investigación HUM-773) de la Consejería de Educación, Cultura y Deporte (Junta de Andalucía). Nuestro agradecimiento a Jesús Bernardo Otero Costas, catedrático de Fisiología, y a la dirección de su Departamento, por facilitarnos y permitirnos reproducir las figuras 1 a 4 y 7 de este artículo. También al personal de las bibliotecas Xeral y Facultad de Medicina de la Universidad de Santiago, y del Instituto de Estudios Gallegos Padre Sarmiento, del CSIC.
\end{abstract}

** Grupo de Investigación GI-1565 OARMA (USC).

Copyright: (C) 2016 CSIC. Este es un artículo de acceso abierto distribuido bajo los términos de una licencia de uso y distribución Creative Commons Attribution (CC-by) España 3.0.

Cómo citar/Citation: Guillermo Olagüe de Ros y Fernando J. Ponte Hernando, "Intentos de renovación de algunas disciplinas experimentales en la facultad de Medicina de Santiago: los cursos de Paul Hoffmann (1923 y 1924), Amédée Guy (1928) y Eduard Reichenow (1935)", Cuadernos de Estudios Gallegos, 63, núm. 129 (2016), págs. 387-415, DOI: http://dx.doi. org/10.3989/ceg.2016.129.10 
INTENTOS DE RENOVACIÓN DE ALGUNAS DISCIPLINAS EXPERIMENTALES EN LA FACULTAD DE MEDICINA DE SANTIAGO: LOS CURSOS DE PAUL HOFFMANN (1923 Y 1924), AMÉDÉE GUY (1928) Y EDUARD REICHENOW (1935)*

RESUMEN

Los años 20 y 30 del pasado siglo fueron de renovación y cambio en la Facultad de Medicina de Santiago de Compostela, una institución tradicionalmente provinciana, equivocadamente ensalzada por la prensa local y ciertos sectores de la propia Facultad. A la renovación del profesorado, con la llegada de nuevos catedráticos muy bien formados, hay que sumar la presencia de un grupo de Profesores Auxiliares ambiciosos en el plano científico y muy dedicados a sus tareas investigadoras y docentes. La crisis vivida en Alemania tras la I Guerra Mundial fue aprovechada por la Facultad de Santiago, que supo atraerse a varios profesores alemanes y franceses para impartir cursos teórico-prácticos al objeto de cubrir sus carencias formativas en varias disciplinas básicas. Se estudian las estancias y las consecuencias de la presencia en Santiago del fisiólogo germano Paul Hoffmann (1884-1962), de Amédée Guy (1882-1957), microbiólogo francés, y del parasitólogo alemán Eduard Reichenow (1883-1960).

Palabras Clave: Facultad de Medicina, Santiago de Compostela, renovación docente, disciplinas básicas, Paul Hoffmann (1884-1962), Amédée Guy (1882-1957), Eduard Reichenow (1883-1960).

\section{INTENTOS DE RENOVACIÓN DALGUNHAS DISCIPLINAS EXPERIMENTAIS NA FACULTADE DE MEDICIÑA DE SANTIAGO: OS CURSOS DE PAUL HOFFMANN (1923 Y 1924), AMÉDÉE GUY (1928) E EDUARD REICHENOW (1935)}

RESUMO

Os anos 20 e 30 do pasado século foron de renovación e cambio na Facultade de Medicina de Santiago de Compostela, tradicionalmente unha institución provinciana, indebidamente eloxiada pola prensa local e algúns sectores da Facultade. Á renovación do profesorado, coa chegada de novos catedráticos altamente cualificados, hai que engadir a presencia dun grupo de Profesores Auxiliares científicamente ambiciosos e moi adicados ó seu traballo de investigación e ensino. A crise vivida en Alemaña trala Primeira Guerra Mundial foi aproveitada pola Facultade de Santiago, que foi quen de atraer a varios profesores alemáns e franceses para impartir cursos teórico-prácticos, a fin de satisfacer as súas deficiencias educativas en varios cursos de disciplinas básicas. Estudánse as estancias e as consecuencias da presenza en Santiago do fisiólogo xermano Paul Hoffmann (1884-1962), de Amédée Guy (1882-1957), microbiólogo francés, e do parasitólogo alemán Eduard Reichenow (1883-1960). Palabras clave: Facultade de Medicina, Santiago de Compostela, renovación docente, disciplinas básicas, Paul Hoffmann (1884-1962), Amédée Guy (1882-1957), Eduard Reichenow (1883-1960).

\section{ATTEMPTS TO RENEW SOME EXPERIMENTAL DISCIPLINES IN THE FACULTY OF MEDICINE OF SANTIAGO: THE COURSES BY PAUL HOFFMANN (1923 AND 1924), AMÉDÉE GUY (1928) AND EDUARD REICHENOW (1935)}

Abstract

The years 20s and 30s of the last century were profound renewal and change in the Faculty of Medicine of Santiago de Compostela, a traditionally parochial institution, wrongly praised by the local press and certain sectors of the own faculty. To the renewal of the faculty, with the arrival of new professors very well formed, it must be added the presence of a group of assistant professors ambitious at the scientific level and very devoted to their research and teaching tasks. The crisis experienced in Germany after the First World War was exploited by the Faculty in Santiago, which was able to attract a number of French and German professors to teach theoretical and practical courses in order to cover their training gaps in basic disciplines. We study stays and the consequences of the presence in Santiago of the physiologist Paul Hoffmann (1884-1962), Amédée Guy (1882-1957), a French microbiologist, and Eduard Reichenow (1883-1960), a German parasitologist.

KeY words: School of Medicine, Santiago de Compostela, faculty renewal, basics disciplines, Paul Hoffmann (1884-1962), Amédée Guy (1882-1957), Eduard Reichenow (1883-1960). 
Recibido/Received: 24/03/2015

Aceptado/Accepted: 31/07/2015

A Javier

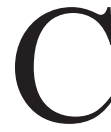

ooperación internacional, internacionalismo y universalismo, fueron términos sinónimos usados con profusión por los científicos de todas las ramas hasta las puertas de la Gran Guerra. Con su utilización querían recalcar el carácter extranacional de la ciencia, su independencia de los gobiernos y su autonomía como forma de conocimiento". Pero a la conclusión de la Guerra la ciencia dejó de ser internacional para pasar a ser un instrumento al servicio de los poderes políticos de cada país.

Al terminar la I Guerra Mundial Alemania, la potencia perdedora, fue expulsada de todos los foros científicos internacionales. El International Research Council (Consejo Internacional de Investigación), fundado en 1919, que agrupó a los países triunfadores y a los que habían permanecido neutrales, excluyó de su seno a los Poderes Centrales. Una de las consecuencias de este ostracismo fue la imposibilidad de los alemanes para participar en congresos internacionales (el $60 \%$ de los celebrados entre 1919 y 1952 se efectuaron mayoritariamente sin su presencia). Por otro lado, la producción científica alemana descendió brutalmente con motivo de la guerra, pero una década después, en los 30 , recuperó más de la mitad de su posición internacional. Conviene recordar que antes de 1914 casi el $35 \%$ de la ciencia circulante internacional era alemana ${ }^{2}$. Expresión de este radical rechazo al mundo alemán fue la actitud de George Francis Hampson (1860-1936)

\footnotetext{
1 Guillermo Olagüe de Ros, "El internacionalismo científico de principios del siglo XX y su refuerzo de las ciencias nacionales", en Gregorio González Alcaide, Javier Gómez Ferri y Víctor Agulló Calatayud (eds.), La colaboración científica: una aproximación multidisciplinar, València, Nau Llibres, 2013, págs. 109-118, pág. 109.

2 Brigitte Schroeder-Gudehus, Les scientifiques et la paix. La communauté scientifique internationale au cours des années 20, Montréal, Les Presses de l'Université de Montréal, 2014. Guillermo OlagüE DE Ros, "El internacionalismo científico de principios del siglo XX y su refuerzo de las ciencias nacionales", en Gregorio González Alcaide, Javier Gómez Ferri y Víctor Agulló Calatayud (eds.), La colaboración científica: una aproximación multidisciplinar, València, Nau Llibres, 2013, págs. 109-118, pág. 111.
} 
de no incluir en una publicación de su especialidad, la entomología, referencias ni citas de trabajos de autores alemanes, a los que consideraba "enemigos del género humano".

Frente al boicot de los vencedores, Alemania creó redes de colaboración con países que se habían mantenido neutrales en la contienda, fundamentalmente europeos, como España, y suramericanos, fundando en ellos y en la propia Alemania organismos culturales defensores de la cultura germánica ${ }^{3}$.

El buque insignia de ese iberoamericanismo germánico en biomedicina fue el Instituto de Enfermedades Tropicales y Navales de Hamburgo (IETNH) (Institut für Schiffs- und Tropenkrankheiten), un organismo de investigación fundado por Bernhard Nocht (1857-1945)4. La Revista Médica de Hamburgo (1920-1926), La Medicina Germano-Ibero-Americana (1923-1927), y la Revista Médica Germano Ibero-Americana (1928-1938) fueron el vehículo de ese pro-americanismo, aunque la presencia de artículos firmados por españoles o sudamericanos fue mínima (entre 1924 y 1927, por ejemplo, la presencia española en La Medicina Germano-Ibero-Americana representó el 2'79\%, 215 trabajos de autores alemanes frente a 6 de españoles) $)^{5}$. No debemos olvidar que en el equipo directivo de estas revistas no figuró ningún español. Como han señalado Magali Romero Sá y André Felipe Cândido Da Silva estas tres revistas estuvieron al servicio de la industria química y farmacéutica de Alemania ${ }^{6}$.

Para contrarrestar esta aproximación de Alemania al mundo hispano-americano, se creó en Francia en 1912 la UMFIA (Unión Médica Franco-Íbero-Americana) que perduró hasta 1940 y que conoció su máximo esplendor en las décadas

\footnotetext{
3 Un espléndido panorama de esa política cultural hasta la Guerra Civil en Jesús de la Hera MARTíNEZ, La política cultural de Alemania en España en el periodo de entreguerras, Madrid, CSIC, 2002, págs. 11-336. También es importante el libro editado por Sandra Reвок, Traspasar fronteras: un siglo de intercambio científico entre España y Alemania. Über Grenzen hinaus: ein Jahrhundert deutsch-spanische Wissenschaftsbeziehungen, Madrid, CSIC, 2009, que contiene diecisiete estudios, doce de ellos centrados en la ciencia.

4 Ernst Georg NAUCK, "50 Jahre Hamburger Tropeninstitut", Zeitschrift für Tropenmedizin und Parasitologie, 2 (1950), págs. 151-175.

5 Datos extraídos a partir del análisis de los tomos de dicha revista, correspondientes a esos años, que se conservan en la Biblioteca de la Facultad de Medicina de la Universidad de Santiago de Compostela.

6 Magali Romero SÁ y André Felipe Cândido Da SiLva, "La Revista Médica de Hamburgo y la Revista Médica Germano-Ibero-Americana: diseminación de la medicina germánica en España y América Latina (1920-1933)", Asclepio, 62 (2010), págs. 7-34; Magali Romero SÁ y André Felipe Cândido da Silva, "Por entre as páginas do imperialismo germânico na América Latina: a Revista Médica de Hamburgo e a Revista Médica Germano-Ibero-Americana (1920-1933)", Associação Nacional de História-ANPUH. XXIV Simpósio Nacional de História, 2007, [en línea], disponible en <http:// anpuh.org/anais/wp-content/uploads/mp/pdf/ANPUH.S24.0893.pdf $>$ [Consultado: 14/01/2015].
} 
de los 20 y $30^{7}$. En su proceso fundacional jugaron un papel destacado Alberto Bandelac de Pariente (1875-1943), médico honorario de la Embajada española en París, y Louis Dartigues (1869-1940), un cirujano y ginecólogo de prestigio. La UMFIA contó con una revista propia, la Revue de l'UMFIA, que estuvo activa entre 1925 y 1940. Como ha puesto de manifiesto Isabelle Renaudet la UMFIA se topó en España con la germanofilia de buena parte de los médicos, muchos de ellos formados en Alemania, por lo que los socios hispanos de esta asociación fueron un núcleo reducido, apenas un diez por ciento del total. Lo mismo sucedió con la revista. Entre 1925 y 1940 solo se publicaron dos artículos originales de españoles, y una veintena de trabajos menores. Para potenciar las relaciones la UMFIA estableció una política de intercambio científico, por la cual médicos españoles, fundamentalmente de Madrid, Barcelona y Zaragoza, las ciudades con mayor presencia de socios, y también estudiantes, realizaron visitas a instituciones profesionales francesas. No nos consta que de estos intercambios se beneficiaran médicos y estudiantes gallegos. Una postura favorable a la UMFIA la adoptó Mundial Magazine (1911-1914), una revista editada en París íntegramente en castellano y dirigida por Rubén Darío, de claro corte hispanoamericanista, que en 1913 publicó un artículo de Louis Dartigues y Alberto Bandelac de Pariente sobre los fines y proyectos de dicha Unión ${ }^{8}$. Un año después, el grupo de médicos españoles que en marzo estuvieron en París para conocer instituciones francesas, en un viaje patrocinado por la revista madrileña España Médica, contó con el apoyo entusiasta de la UMFIA9 .

En este panorama internacional que acabamos de comentar hay que situar el auténtico desembarco de lo más granado de la ciencia alemana en nuestro país a partir de la década de los veinte. Es sabido que en febrero y marzo de 1923 Albert

\footnotetext{
7 España también cultivó ese hispanoamericanismo pero con nulos resultados. Un análisis de las tentativas españolas en: Guillermo Olagüe de Ros, "La Unión Médica Hispano-Americana (1900) y su contribución al internacionalismo científico", Dynamis, 26 (2006), págs. 151-168; Guillermo OlaGÜE DE Ros, "La colaboración hispano-latinoamericana en los orígenes y desarrollo del movimiento documental europeo contemporáneo (1900-1920)", Encontros Bibli: Revista Eletrônica de Biblioteconomia e Ciência da Iformaçao, núm. esp., $2^{\circ}$ sem. (2006), págs. 82-95, [en línea], disponible en $<$ https://periodicos.ufsc.br/index.php/eb/article/view/1518-2924.2006v11nesp2p82/429> [Consultado: 26/06/2015]. Sin duda, el mayor logro de ese acercamiento hispanoamericanista fue la Biblioteca América (1926), fruto de la donación a la Universidad de Santiago de Gumersindo Busto, un compostelano emigrado a América (Pilar Cagiao Vila y Eduardo Rey Tristán, "La Biblioteca América de la Universidad de Santiago en su centenario (1904-2004)", Anuario Americanista Europeo, núm. 3 (2005), págs. 415-428).

8 "Los médicos y la corriente de amistad Franco-Ibero-Americana", Mundial Magazine, 4 (1913), págs. 849-851, [en línea], disponible en < http://hemerotecadigital.bne.es/results.vm?q=parent:000427504\&lang $=\mathrm{es}>$ [Consultado: 20/06/2015].

9 “Los Viajeros de «España Médica» en París”, España Médica, 4 (1914), núm. 114, págs. 1-17. Dado el éxito del viaje, meses después se hizo una segunda edición ("El Segundo Viaje Científico de «España Médica» a París”, España Médica, 4 (1914), núm. 125, págs. 1-15).
} 
Einstein impartió conferencias en Barcelona, Madrid y Zaragoza, cuestión que ha sido bien estudiada por Thomas F. Glick ${ }^{10}$. Pero Einstein fue la punta de un iceberg. A poco que se indague en la prensa periódica nacional, se encontrarán decenas de noticias sobre la estancia en nuestro país de conferenciantes y cursillistas germánicos.

El ostracismo de Alemania posbélico coincidió también con un importante esfuerzo de apertura de las universidades españolas, tanto dentro de España como al extranjero. Por un lado, se quiso romper con el ensimismamiento de las Universidades y abrir sus puertas a la sociedad donde estaban insertas. A partir de 1908 profesores universitarios salieron de sus cátedras y culturizaron a la sociedad impartiendo conferencias sobre aquellas materias en las que eran expertos. Sociedades culturales y obreras, organismos oficiales, institutos y escuelas de magisterio, acogieron a esos profesores que rompían con el secular recogimiento universitario ${ }^{11}$.

Con el objeto de elevar el nivel de las Universidades la Junta de Ampliación de Estudios (JAE), creada en 1907, estableció una inteligente política de becas hasta 1936. La Guerra Civil interrumpió su actividad. Hasta 1923, por ejemplo, la JAE concedió 3604 ayudas, de las cuales aproximadamente el 50\% se destinó a ciencias de la salud. Del total de subvenciones un $40 \%$ lo fueron para ampliar estudios en países de lengua y/o cultura alemana ${ }^{12}$.

\footnotetext{
${ }^{10}$ Thomas F. GLICK, Einstein y los españoles. Ciencia y sociedad en la España de entreguerras, Madrid, CSIC, 2005.

${ }^{11}$ Hemos podido reunir más de 200 noticias, aparecidas en la prensa diaria gallega, anunciando conferencias de extensión universitaria en instituciones de esa Comunidad. Véanse los portales BiBLIOTECA DE GaLicia. Galiciana, Hemeroteca Digital ( $<\mathrm{http}$ //www.galiciana.bibliotecadegalicia.xunta.es/es/ publicaciones/listar_numeros.cmd $>)$, Biblioteca Nacional de España. Hemeroteca Digital $(<\mathrm{http} / / /$ www.bne.es/es/Catalogos/HemerotecaDigital/ $>$ ) y Ministerio de Educación, Cultura y Deporte, Biblioteca Virtual de la Prensa Histórica (<http://prensahistorica.mcu.es/es/consulta/busqueda. cmd $>$ ). Con ese fin educativo y cultural, pero fuera del ámbito universitario, hay que mencionar la Universidad Popular de Coruña, fundada en 1906 (Antón CAPELÁN REY, "Contribucións a unha historia da Universidade Popular da Coruña”, Sarmiento, 3 (1999), págs. 25-64)

${ }^{12}$ Datos elaborados a partir de la sección CRONOS del archivo en línea de la JAE. RESIDENCIA DE Estudiantes, Archivo de la JAE [en línea], disponible en <http://archivojae.edaddeplata.org/jae_app/> [Consultado: 15/12/2014]. Ricardo Gurriarán ha constatado que entre 1910 y 1920 el $10 \%$ de las pensiones concedidas por la JAE fueron a gallegos, y de ellas un $50 \%$ lo fueron a médicos (Ricardo Gurriarán, Ciencia e conciencia na Universidade de Santiago (1900-1940). Do influxo institucionista e a JAE á depuración do profesorado, Santiago de Compostela, Servizo de Publicacións da Universidade de Santiago de Compostela, 2006, pág. 168. Esta monografía ofrece además un rico panorama sobre la presencia de la JAE en Galicia).
} 
La enseñanza de la Fisiología en la Facultad de Medicina de Santiago de Compostela (1875-1934)

En Santiago las disciplinas básicas experimentales, fundamento de la medicina de laboratorio, fueron minusvaloradas en la enseñanza médica prácticamente hasta la década de los treinta del siglo XX. Es decir, casi cuarenta años después de que fueran una realidad en buena parte de las facultades de medicina españolas. La estancia en Santiago de varios profesores extranjeros en los años veinte y treinta vino a evidenciar y suplir de manera clara esa carencia formativa. Nos centraremos básicamente, por su duración y consistencia, en las del fisiólogo alemán Paul Hoffmann, en 1923 y 1924, la posterior del microbiólogo francés Amédée Guy (1882-1957) de 1928, siendo decano Piñeiro Pérez, y el curso de Parasitología dado en 1935 por Eduard Reichenow (1883-1960), durante el decanato del catedrático de Farmacología Antonio Novo Campelo (1878-1948).

La cátedra de Fisiología compostelana fue ocupada entre 1875 y 1918 por Ramón Varela de la Iglesia (1845-1922). Poco motivado por la asignatura de la que era responsable, se inclinó más por la histología y anatomía patológica, aunque en estas materias tampoco se prodigó mucho científicamente, pues Varela fue de corta producción original. Bien es cierto que gracias a su labor traductora los médicos españoles dispusieron muy tempranamente de las más notables obras de la medicina alemana de su tiempo, pues tradujo entre 1877 y 1883 casi dos centenares de la Colección de Conferencias Clínicas de Richard Volkmann (1830-1889). También contribuyó a la difusión de los adelantos médicos foráneos mediante la Revista General de los Progresos de la Medicina en Europa y América (1877-1883), un repertorio de resúmenes de artículos editados en revistas internacionales ${ }^{13}$.

A pesar de que en 1915 había cumplido la edad reglamentaria de jubilación, Varela consiguió seguir al frente de la cátedra durante dos años más. Desde octubre de 1920 y de nuevo desde ese mismo mes del año 1923, Germán Caamaño Solar (n. 1885), profesor auxiliar de la disciplina, se hizo cargo de la enseñanza hasta 1927, fecha en la que ocupó la cátedra José María García-Blanco Oyarzábal (1898-1973) por traslado desde la de Granada ${ }^{14}$.

\footnotetext{
${ }^{13}$ Juan José FernándeZ Tejueiro, Ramón Varela de la Iglesia (1845-1922). Positivismo e Histología en Fonseca, Tesis de Doctorado, Universidad de Santiago de Compostela, 2007; José María LóPEZ PIÑERo, Diccionario de histórico de la ciencia moderna en España, vol. 2, Barcelona, Ediciones Península, 1983, págs. 396-397; R. GuRriarán, Ciencia ..., págs. 94-102.

${ }^{14}$ Archivo Histórico de la Universidad de Santiago de Compostela (AHUS), Expediente docente de Don Germán Caamaño Solar. Sobre García-Blanco: Rafael Sisto, "José María García-Blanco Oyarzábal", en Álbum da Ciencia. Culturagalega.org. [en línea], disponible en <http://www.culturagalega.org/albumdaciencia/detalle.php?id=387> [Consultado: 25/02/2015], y Bernardo José María Hernández Iranzo, José María García-Blanco Oyarzábal. "El hombre y su Obra". Una
} 


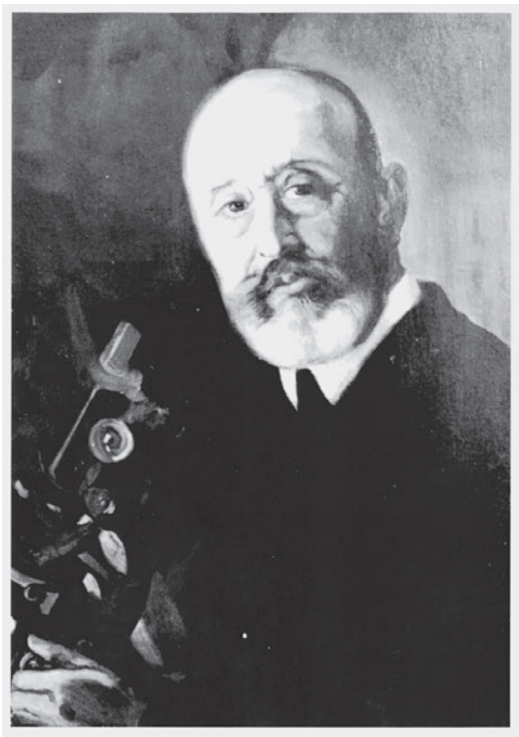

Figura 1. Ramón Varela de la Iglesia (1845-1922).
Uno de los primeros auxiliares en Fisiología fue el burgalés Misael Bañuelos García (1887-1954), estando aún en activo Varela de la Iglesia. Formado en Madrid (1906-1912), tras doctorarse en 1913 con una memoria de temática fisiológica, por permuta marcha en 1914 a Santiago de Compostela como Auxiliar de Fisiología e Higiene. Desde esa fecha, y hasta la marcha de Varela, Bañuelos se dedicó en exclusiva a esta disciplina ${ }^{15}$. Entre 1916 y agosto 1917 fue becado por la JAE para trabajar en Berna con Hugo Kronecker, Herman Sahli y Leon Asher sobre fisiología del sistema nervioso. Esta total dedicación la llevó también fuera de las aulas. En noviembre de 1919 impartió un curso de Fisiología especial del Sistema Nervioso y una conferencia sobre "investigaciones de la dinámica cardiaca" en el Patronato

de los Luises de la capital gallega. Todas sus publicaciones entre 1913 y 1920 , como era de esperar, versan sobre fisiología. Como bien señaló Juan José Barcia Goyanes, Bañuelos tenía una fuerte inclinación por la clínica, por lo que a pesar de su magnífica preparación como fisiólogo, obtuvo en 1920 por oposición la cátedra de Patología Médica de Valladolid, que regentaría hasta su jubilación ${ }^{16}$.

Tras la marcha de Bañuelos se hizo cargo de la docencia de la disciplina Germán Caamaño Solar, como ya hemos adelantado, que la desempeñó prácticamente

etapa de la Bioquímica y de la Fisiología valenciana (1941-1968), València, Universitat-Servei de Publicacions, 2003, un estudio centrado en la etapa valenciana de García-Blanco, pero que contiene abundante información de su paso por Santiago, [en línea], disponible en <www.tdx.cat/bitstream/ handle/10803/9888/hernandez.pdf $>$ [Consultado 26/06/2015].

${ }^{15}$ En el curso 1916-1917 ya figura como auxiliar de Varela de la Iglesia ("Universidad de Santiago. Facultad de Medicina", Gaceta de Galicia, 44 (1916), núm. 188, pág. 1).

${ }^{16}$ Juan Manuel Granda Juesas, Don Misael Bañuelos. Medicina, antropología, sociedad, Valladolid, Secretariado de Publicaciones de la Universidad, 1987; Residencia De Estudiantes, Archivo de la $J A E$, Expediente Personal JAE/215-69, [en línea], disponible en $<$ http://archivojae.edaddeplata.org/ jae_app/>. Según Juan José Barcia Goyanes, Bañuelos era el docente de Fisiología cuando llegó Hoffmann (Juan José BARCia, La saga de los Barcia, Valencia, Artes Gráficas Soler, 2003, pág. 124). Este dato se incluye también en una entrevista que Hernández Iranzo hizo a Barcia acerca de la etapa valenciana de García-Blanco, pero en la que Barcia introdujo algunos recuerdos de su permanencia compostelana, como el curso que impartió Hoffmann (B. J. M. Hernández Iranzo, José María García-Blanco..., págs. 234-235). 
hasta la venida de García-Blanco ${ }^{17}$. Para reforzar la enseñanza de la asignatura el 3 de diciembre de 1921 la Facultad acordó nombrar a Caamaño responsable de la cátedra vacante, ocupando su plaza de auxiliar Francisco Bacariza Varela (1885-1933), quien se dedicaría después de por vida a la neurología y psiquiatría ${ }^{18}$.

Germán Caamaño, natural de Negreira (Coruña), se licenció en la Facultad de Medicina compostelana en 1907. Seis años después obtuvo el grado de doctor con una memoria sobre "La fatiga cerebral y sus relaciones con la fatiga neurasténica”. Como médico ejerció la medicina interna y optó en múltiples ocasiones a cátedras de Patología General y Médica de varias universidades, aunque sin éxito. Fue también médico de Negreira y Santiago e Inspector de Sanidad, y durante temporadas dirigió algunos balnearios, como el de Caldas de Reis y Verín. Aficionado a la filosofía publicó un libro de ensayos sobre esta temática en 1948 (Luz en tu sombra $)^{19}$.

\section{LA doble Visita del fisiólogo Paul Hoffmann, 1923 y 1924}

La estancia de Hoffmann es, sin duda, la más notable, tanto por su prestigio como por las características que rodearon su presencia en Santiago. La visita de Hoffmann a Galicia reviste dos novedades interesantes: por un lado, la larga duración de sus estancias, pues en su primer viaje (1923) permaneció en Santiago prácticamente tres meses, en el segundo mes y medio (1924) y en 1941 casi un mes. Y en segundo lugar, las condiciones de su venida, pues si aceptamos la opinión de Juan José Barcia Goyanes, por entonces un estudiante en la Facultad

\footnotetext{
17 "Curso 1925-1926. Facultad de Medicina. Cuadro de Enseñanza", El Compostelano, 6 (1925), núm. 1071, 8 octubre, pág. 3. Los artículos aparecidos en la prensa de la época y citados en este trabajo se han obtenido de los portales señalados en la nota 8 de este trabajo.

${ }^{18}$ Libro de Registro de las Actas de las sesiones de la Facultad de Medicina (24 de octubre de 1917 a 1 de diciembre de 1929): Sesión de 3 de diciembre de 1921 (AHUS, Ref. A-966). Bacariza Varela figura como Auxiliar el 24 de febrero de 1923, pero muy probablemente su nombramiento fuera anterior, tras pasar Caamaño a ocupar provisionalmente la cátedra (Libro de Registro de Comunicaciones de Salida del Decanato de la Facultad de Medicina. 20 de septiembre de 1918 a 24 de julio de 1928, AHUS, Ref. A-852). Bacariza entró a trabajar en el manicomio de Conxo en 1927 y fue director del mismo entre 1927 y 1930. Una breve semblanza biográfica en: David SIMÓN LORDA, Locura, medicina, sociedad: Ourense (1875-1975), Ourense, Fundación “Cabaleiro Goás"-Complexo Hospitalario de Ourense, 2005, págs. 214-215, [en línea], disponible en $<\mathrm{http}$ :/dialnet.unirioja.es/ descarga/libro/265395.pdf> [Consultado el 26/06/2015].

${ }^{19}$ Sobre Caamaño véanse X. Amancio LiÑares Giraut, "Gaveando no Agrarismo Barcalés. La Federación de Negreira y Baña (1911)", en Xesús Balboa López y Herminia Pernas Oroza (coords.), Entre nós. Estudios de Arte, Xeografía e Historia en Homenaxe ó Profesor Xosé Manuel Pose Antelo, Santiago de Compostela, Universidade-Servicio de Publicacions, 2011, pág. 872, nota a pie de página 13 y Gran Enciclopedia Gallega, Santiago-Gijón, Silverio Cañada editor, 1974, vol. IV, pág. 98.
} 


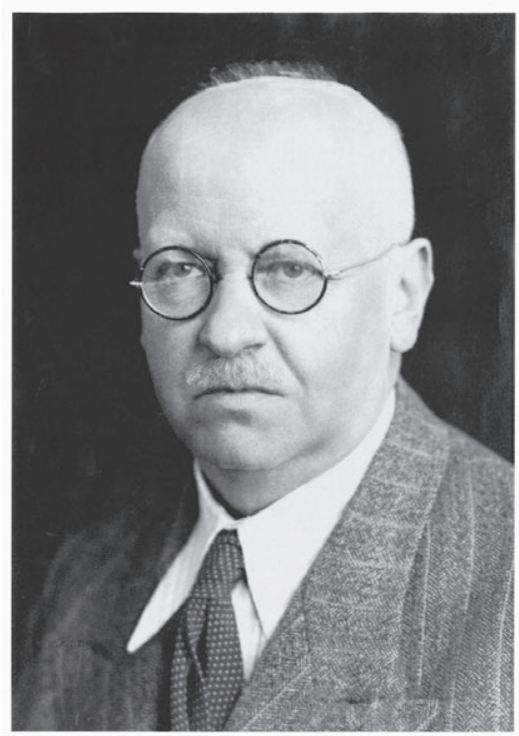

Figura 2. Paul Hoffmann (1884-1962).

compostelana, Hoffmann fue contratado en 1923 como docente por la Facultad, situación excepcional en comparación con otras facultades españolas, lo que suponía una actividad reglada para dar un curso a los estudiantes sobre técnicas de investigación en fisiología experimental, además de la exposición de conferencias magistrales ${ }^{20}$.

Paul Hoffmann (1884-1962) se formó en las Facultades de medicina de Leipzig, Marburgo y Berlín. En 1909 obtuvo el grado de doctor con una memoria sobre "las llamadas líneas de reversión de las fibras musculares cardiacas", que completó en Leipzig en el Instituto de Patología de Felix Jacob Marchand (1846-1928), un renombrado especialista mundial en arterioesclerosis. Durante el siguiente trienio, Hoffmann fue Asistente en el Instituto de Fisiología de Berlín, que dirigía Max Rubner (1854-1932), un experto investigador del metabolismo y de la nutrición, donde comenzó a familiarizarse con la electrofisiología muscular. En 1912 alcanzó la habilitación en Wurzburgo con un estudio sobre las corrientes de acción en el músculo sometido a veratrina, lo que le permitió ser nombrado privatdozent en el Departamento de Fisiología de la Universidad de Wurzburgo que dirigía Max von Frey (1852-1932), inventor del pulmón artificial (1885) y un renombrado estudioso del pulso ${ }^{21}$. Su tesis doctoral y su trabajo de habilitación fueron el punto de partida de una fecunda trayectoria investigadora dedicada a la fisiología neuromuscular que le acompañó durante toda su vida profesional ${ }^{22}$.

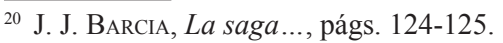

${ }^{21}$ Einz-Gerd Zimmer, The Heart-Lung Machine was Invented Twice -the first time by Max von Frey", Clinical Cardiology, 26 (2003), págs. 443-445.

${ }^{22}$ Wilhem Blasius, "Zur Geschichte der Reflexlehre unter besonderer Würdigung des Beitrages von Paul Hoffmann”, Deutsche Zeitschrift für Nervenheilkunde, 186 (1965), págs. 475-495; Richard Jung, "Paul Hoffmann 1884-1962", Reviews of Physiology, Biochemestry and Experimental Pharmacology, 61 (1969), págs. 1-17; Albrecht Stuppler, "Hoffmann, Paul”, Neue Deutsche Biographie (NDB), 9 (1972), págs. 400-401, Deutsche Biographie [en línea], disponible en <http://www.deutsche-biographie.de/pnd121156826.html> [Consultado: 15/01/2015]. De todos los trabajos biográficos sobre Hoffmann que hemos analizado, tan sólo Peter Voswinckel recuerda su dilatada vinculación con la Universidad de Santiago (Peter Voswinckel, "Hoffmann, Paul", Biographisches Lexikon der hervorragenden Ärzte der letzen fünfzig Jahre, Vol. 3, Hidelsheim-Zürich-New York, Georg Olms
} 
En 1917 fue nombrado profesor en Friburgo, y en 1924 sucedió a Johannes von Kries (1853-1928) en la dirección del Departamento de Fisiología de dicha universidad ${ }^{23}$.

Cuando Hoffmann llegó a Santiago ya era, pues, un científico muy reconocido internacionalmente. Antes de la Primera Guerra Mundial, por ejemplo, ya había publicado 32 artículos en las más prestigiosas revistas médicas alemanas, y al llegar a Santiago superaban la cincuentena. En marzo de 1915 dio a luz en la muniquesa Medizinische Klinik un trabajo "Acerca de un método para evaluar el éxito de una sutura nerviosa", en el que describió, pocos meses antes que el clínico francés Jules Tinel (1879-1952), el "signo H", que consiste en la sensación de hormigueo en el extremo distal de un miembro cuando se percute por encima de un tronco nervioso seccionado ${ }^{24}$.

De la documentación consultada no hemos podido determinar de quien partió la iniciativa de traer a Hoffmann a Santiago. Sin embargo, todo parece apuntar a que fue el decano de Medicina, Francisco Piñeiro Pérez (1864-1951), con el consenso del claustro médico, el que consideró esa opción. Piñeiro, catedrático de cirugía ${ }^{25}$, no fue precisamente un gran publicista ni investigador. Sin embargo, fue un magnífico gestor. Cuando fue alcalde de Santiago promovió en 1909 la creación de una nueva Facultad de Medicina, que no se concluyó hasta 1928, y también durante su mandato como decano (1921-1931), se procedió al traslado al nuevo centro docente de la rúa de San Francisco ${ }^{26}$. La Facultad de Medicina

Verlag, 2002, pág. 663). Una nota biográfica con motivo de su vista a Santiago en: Revista Médica Gallega, 3 (1923), pág. 103.

${ }^{23}$ Johannes Von Kries (1853-1928) fue, sin duda, el más importante estudioso de su tiempo sobre la fisiología de la visión (Walter HeInz, "Kries, Johannes von", Neue Deutsche Biographie (NDB), 13 (1982), pág. 46, Deutsche Biographie [en línea], disponible en $<$ http://www.deutsche-biographie. de/ppn116545844.html> [consultado: 07/03/2015].

${ }^{24}$ Jason M. Sansone, Angela M. Gatzke, Florence Aslinia, Loren A. Rolak y Steven H. Yale, “Jules Tinel (1879-1952) and Paul Hoffmann (1884-1962)", Clinical Medicine \& Research, 4 (2006), págs. 85-89.

${ }^{25} \mathrm{Al}$ decir de Barcia, Piñeiro era un buen cirujano, que además tenía acumulada las cátedras de oftalmología y dermatología (Juan José BARCIA, La saga ..., pág. 129). Una nota sobre Piñeiro en Ricardo Gurriarán, Xesús Otero Costas y José Manuel García Iglesias, a galería de decanos da Facultade de Medicina, Santiago de Compostela, Servizo de Publicacións e Intercambio Científico, 2014, s. p.

${ }^{26}$ Margarita Barral Martínez, "O mecenado de Montero Ríos na Universidade de Santiago", Semata, 10 (2008), págs. 222-225. Pedro Pena Pérez, en un artículo publicado el 13 de junio de 1924 en El Compostelano, señalaba que, gracias a la gestión del decano Piñeiro Pérez, la Facultad contaba con una nueva y magnífica instalación de Rayos $\mathrm{X}$, con una sala de conferencias dotada de los últimos adelantos, como un epidiascopio. En próximas acciones se pretendía instalar un aparato de cine y crear un Departamento de Fisiología dotado de los recursos técnicos necesarios para llevar a cabo una labor científica de alta calidad ("En defensa de nuestra Facultad de Medicina”, El Compostelano, (1924), núm. 1291, pág. 3). 
encargó a Novo Campelo, que había sido becado en 1909 en Alemania por la JAE $\mathrm{y}$, ahora, probablemente, por el Patronato de la Universidad, a que ultimara con Hoffmann los últimos detalles para que su venida fuera efectiva y fructífera ${ }^{27}$.

Hoffmann llegó a Coruña el 28 de febrero a bordo del vapor "Sierra Nevada". Apenas pisó tierra le esperaban los profesores Alejandro Rodríguez Cadarso (1887-1933), catedrático de anatomía, Francisco Bacariza Varela, y José Puente Castro (1883-1963), profesor auxiliar y con el tiempo prestigioso cirujano, y con todos ellos emprendió camino a Santiago ${ }^{28}$. Llama la atención que no estuviera entre los presentes Germán Caamaño Solar, encargado de la cátedra.

Para poder llevar en condiciones el curso, el decanato procedió a una amplia reforma de los locales del antiguo laboratorio de Ramón Varela. Entre otras medidas, se agrandó el antiguo, se instalaron tomas de agua y gas, y se adquirieron aparatos, instrumentos y material fungible necesarios para el curso, lo que viene a reforzar la idea de que el laboratorio de Varela era básicamente histológico y poco preparado para trabajos de fisiología. Además, la Facultad nombró ayudantes de Hoffmann a los alumnos Francisco Bacariza, auxiliar de Medicina Legal, Juan Luis Barcia Goyanes (1903-1924) -hermano de Juan José-, interno en Histología, Arturo Cervigón Díaz y Ulpiano Villanueva -internos de Fisiología- y a Luis Sánchez Cardonne.

El 5 de marzo comenzaron las lecciones prácticas. Los inscritos al curso de Fisiología Experimental acudían al laboratorio de 9 a 11 de la mañana y de 4 a 6 de la tarde todos los días lectivos. Los sábados estaban dedicados a las conferencias o clases teóricas, en las que Hoffmann exponía públicamente las tareas realizadas por los veinte alumnos inscritos en el curso y realizaba algunas demostraciones experimentales ${ }^{29}$.

En 1926, dos años después de su óbito, los compañeros de Barcia acordaron publicar con su nombre un libro en el que se recogían los experimentos y conferencias impartidos por Hoffmann, pues había sido encargado por el Decano de

\footnotetext{
${ }^{27}$ Libro de Registro de las Actas de las sesiones de la Facultad de Medicina (24 de octubre de 1917 a 1 de diciembre de 1929). AHUS, Ref. A-966, Acta del 14 de diciembre de 1922, pág. 189. Sobre la pensión de Novo Campelo en Alemania en 1909: Residencia de Estudiantes, Archivo de la JAE, Expediente Personal JAE/106-122, [en línea] disponible en <http://archivojae.edaddeplata.org/ jae app $/>$.

${ }^{28}$ Sobre Rodríguez Cadarso: Ricardo GuRRIARÁn, Ciencia..., págs. 311-314, así como la voz redactada por Ánxela Bugallo para el Álbum da Ciencia y la monografía dedicada a la gestión rectoral de Cadarso de Manuel R. Bermejo Patiño y R. Gurriarán (coords.), Rodriguez Cadarso. Un reitor para un país, Santiago de Compostela, Universidad, 2008.

${ }^{29}$ El Eco de Santiago, 28 (1923), núm. 11.405, 5 de marzo, pág. 2; "Facultad de Medicina de Santiago. Curso de Fisiología Experimental por el profesor Hoffmann", Revista Médica Gallega, 3 (1923), 103-104.
} 


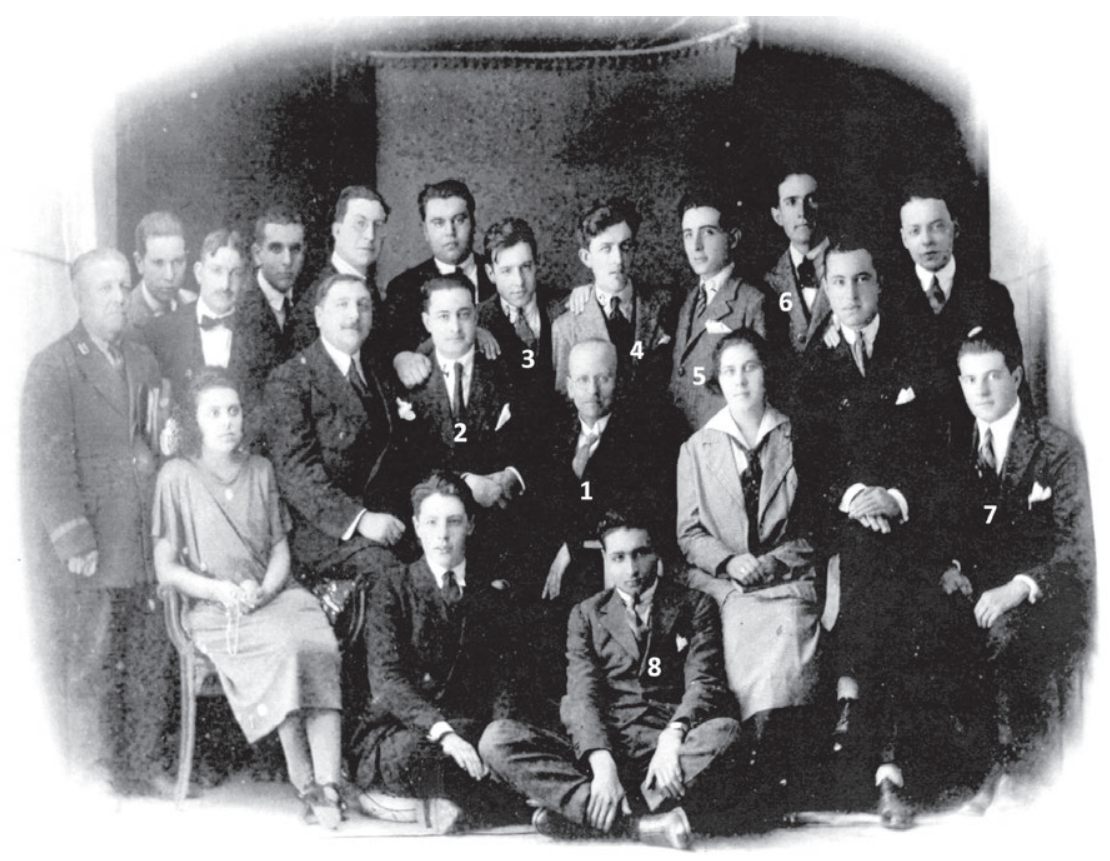

Figura 3. Paul Hoffmann reunido con sus ayudantes del curso de Fisiología Experimental de 1923 [Paul Hoffmann (1). Arturo Cervigón Díaz (2). Juan Luis Barcia Goyanes (3). Ulpiano Villanueva Castro (4). Luis Sánchez Cardonne (5). Ángel Jorge Echeverri (6). Agustín Jorge Echeverri (7).

Cándido Masa (8)].

redactar una memoria-resumen sobre dicho curso ${ }^{30}$. El texto impreso contiene, además, un recordatorio de Caamaño y un prólogo del propio Barcia, piezas que también serían reproducidas el 28 de enero de ese año en El Compostelano ${ }^{31}$.

La obra es sumamente interesante, pues ofrece muy detalladamente toda la actividad de Hoffmann, tanto sus experimentos como una síntesis de las conferencias dadas. Como bien señalaba Barcia, el orden temporal de ambas actividades no se correspondía en el texto con el seguido por Hoffmann durante la celebración del curso, pues algunos ensayos programados tuvieron que ser pospuestos por no disponer momentáneamente de los medios técnicos necesarios, aunque una vez en manos de Hoffmann pudieron celebrarse. En total, la Memoria recoge once experimentos de aparato circulatorio, ocho de sistema muscular y nervioso, cinco

\footnotetext{
${ }^{30}$ Juan Luis Barcia Goyanes, Fisiología Experimental. Memoria-Resumen de los trabajos realizados por el Pr. P. Hoffmann en la Facultad de Medicina, durante los meses de Marzo, Abril y Mayo del Curso 1923, Santiago, Tipografía "La Comercial", 1926.

317 (1926) núm. 1757, pág. 1.
} 
sobre órganos de los sentidos, cuatro de fisioanálisis y tres de física biológica. En total, pues, treintaiuno. En cuanto a las conferencias se consignan ocho: "Investigaciones modernas sobre la función cardiaca", "La respiración externa e interna", "Método de investigación del metabolismo", "El calor animal y la regulación térmica", "Los reflejos", "Las funciones del laberinto estático", "La sensación de los colores y el daltonismo" y "Las ideas modernas sobre la contracción muscular". No cabe duda que en la temática de la tercera conferencia -"Método de investigación del metabolismo"- pesó su relación discipular con Max Rubner, pues como ya adelantamos Rubner era un experto en cuestiones de metabolismo.

La última conferencia de Hoffmann no se recogió en el libro de Barcia. En ella abordó "la ciencia biológica en Alemania durante la guerra y después de la guerra", de la cual dio información El Eco de Santiago en el número correspondiente al 21 de mayo ${ }^{32}$.

El 2 de enero de 1924, ya de regreso en Alemania, El Eco de Santiago publicaba una extensa carta de Hoffmann dirigida a un profesor compostelano, del que no se cita su nombre, en la que agradecía las atenciones que había recibido mientras impartió el curso, le comunicaba que había sido nombrado catedrático en Wurzburgo como sucesor de von Kries, y aseguraba que recibiría con el mayor agrado a cualquier profesional de Compostela que quisiera trabajar con él $\mathrm{l}^{33}$.

El destino de la mayoría de los cinco alumnos de Hoffmann durante su primer curso fue realmente trágico. Tres de ellos fallecieron prematuramente, Francisco Bacariza y Juan Luis Barcia Goyanes, ya señalados, a los que hemos de añadir Luis Sánchez Cardonne (n. 1897), que murió a finales de noviembre de $1928^{34}$. De los otros dos, únicamente Ulpiano Villanueva Castro, como luego comentaremos, pudo desarrollar una actividad normal a largo plazo.

Arturo Cervigón Díaz (n. 1892), el cuarto alumno ayudante, cursó los estudios de medicina en Santiago entre 1920 y 1925, con magníficas calificaciones. Tras graduarse se doctoró en Madrid en 1928 con una memoria acerca La colesterina en la diabetes y las aguas de Mondariz, que publicó en Santiago en $1929^{35}$. Dos años después, en colaboración con Antonia Martínez Casado editó un Manual de prácticas hidrológicas, obra que fue galardonada con el Premio Salgado de la

\footnotetext{
32 "El cursillo de Fisiología práctica. Conferencia final", Eco de Santiago, 28 (1923), núm. 11.467, 21 de mayo, pág. 1.

33 "Una carta del profesor Hoffmann", El Eco de Santiago, 28 (1924), núm. 11.662, 2 de enero, pág. 1.

${ }^{34}$ Luis Sánchez Cardonne, natural de Coruña, cursó sus estudios de Medicina en Madrid (años 1915 a 1918) y Santiago de Compostela (1919 a 1923), en cuya Facultad se graduó en junio de 1923 (AHUS, Legajo 1331, Expediente 3). Noticia de su óbito en Ferrol, ciudad en la que residía con sus padres, en El Pueblo Gallego, 5 (1928), 28 de noviembre, pág. 4.

35 Tipografía "El Eco Franciscano".
} 
Academia Nacional de Medicina en la convocatoria de 1933-19346. En abril de 1931 la JAE le concedió una consideración de pensionado para asistir en París a un curso de Hidrología y Climatología Terapéuticas. Desde que concluyó sus estudios, pues, Arturo Cervigón se desligó de la Universidad Compostelana y se centró en la hidrología médica. En Galicia Clínica publicó tras la Guerra trabajos de su especialidad y dirigió algunos balnearios. Al estallar la Guerra Civil se le abrió expediente de depuración por su condición de masón y por haber figurado como concejal por el Partido Radical en el Ayuntamiento de Santiago (1935), con la consecuencia de una condena prohibitoria para el ejercicio de cualquier cargo público y la imposición de una fuerte sanción económica. Retirado de la vida pública se dedicó a administrar los bienes familiares ${ }^{37}$.

En su segunda estancia en Santiago le acompañó Friedrich Holtz (1889-1967), médico y bioquímico de Wuzburgo. Según el diario vigués Galicia, Hoffmann llegó a Coruña a bordo del trasatlántico "Sierra Ventura" el día 13 de febrero de 1924, y a partir del día 18 inició sus clases y prácticas. Al igual que la primera vez, el objetivo era impartir un cursillo de fisiología experimental, que se prolongaría hasta principios de abril, por tanto, de más corta duración que el primero ${ }^{38}$. Del contenido del mismo el coruñés El Ideal Gallego dio cuenta de la conferencia dada el 24 de febrero sobre "La demostración de los métodos de investigación de los movimientos intestinales de los animales". El Eco de Santiago, por su parte, señalaba que Hoffmann había introducido algunos cambios en relación con la metodología del curso anterior, pues este año se iba a centrar más en química biológica (la presencia de Friedrich Holtz respondía a esta intención docente) ${ }^{39}$. Por desgracia, no hemos localizado más noticias en la prensa.

Hay un tercer viaje de Hoffmann a Galicia, el más breve de todos. Hoffmann llegó a Santiago en noviembre de 1941, en plena Segunda Guerra Mundial, e impartió un curso parecido al de las anteriores ocasiones, es decir, trabajos de laboratorio y conferencias magistrales, pero de muy corta duración. A fines de ese mismo mes regresó a Berlín, tras declinar una invitación de la Universidad de Valencia para que diera en su Facultad de Medicina un cursillo teórico-práctico ${ }^{40}$.

\footnotetext{
${ }^{36}$ Madrid, España.

${ }^{37}$ AHUS, Expediente Personal, Legajo 249, expediente 6. Gran Enciclopedia Gallega, Santiago-Gijón, Silverio Cañada editor, 1974, vol. VI, pág. 147. R. GuRRIARÁn, Ciencia ..., pág. 674.

38 "Santiago. El Dr. Paul Hoffmann", Galicia, (1924), núm. 473, 2, 6 de enero.

39 "Otra conferencia. El notable fisiólogo germano profesor Hoffmann". El Ideal Gallego, 8 (1924), 24 de febrero, pág. 6; "El cursillo del Dr. Hoffmann”, El Eco de Santiago, 28 (1924), núm. 12.010, 25 de febrero, pág. 1.

${ }^{40}$ Los diarios gallegos dieron escasas noticias de esta tercera visita de 1941 de Hoffmann, quizás porque estaban muy ocupados ofreciendo información sobre el curso de la Guerra. Tan sólo dos números de El Pueblo Gallego, de Vigo -en concreto el núm. 17, 5705 (15 de noviembre de 1941),
} 


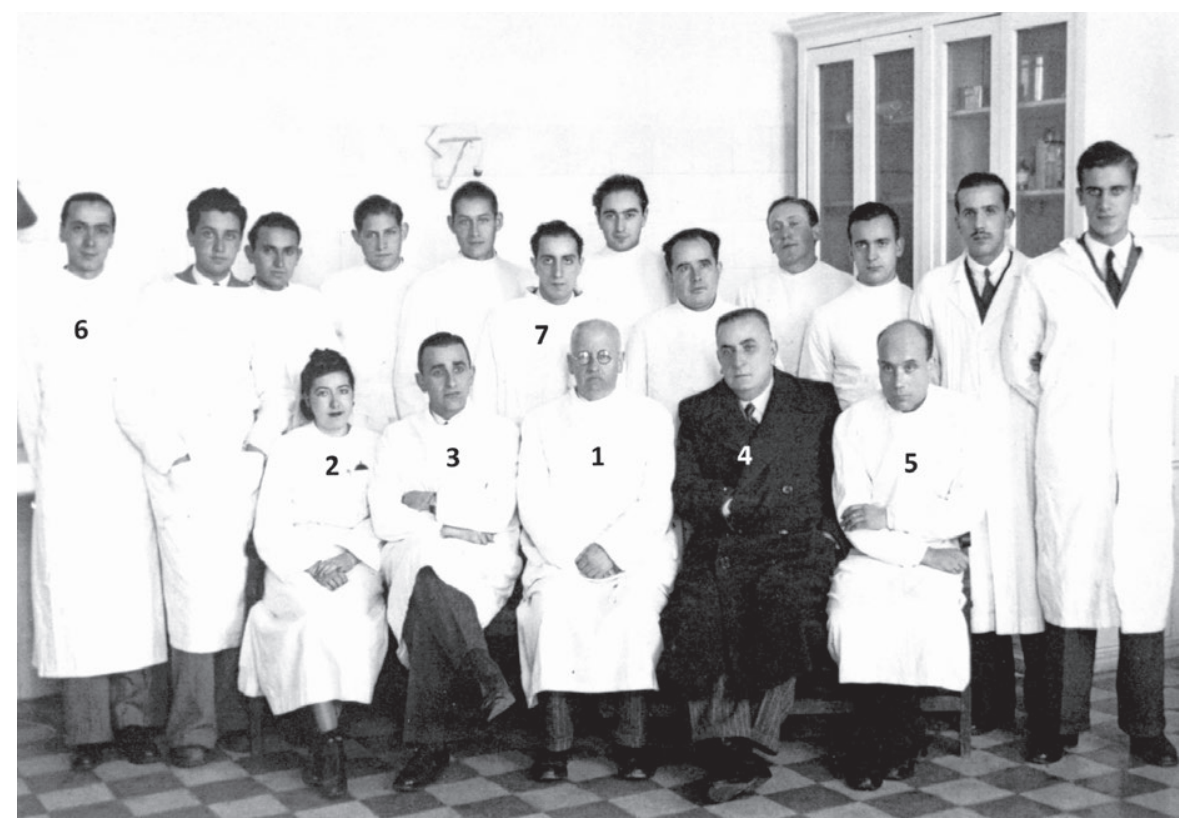

Figura 4. Paul Hoffman y miembros de la cátedra de Fisiología de Santiago de Compostela, con el decano de la Facultad, Antonio Novo Campelo (4), durante el curso que impartió en 1941

[Paul Hoffmann (1). Blanca Matilde Sánchez Díaz (2). Ramiro Sánchez Calvo (3).

Ramón Villarino Ulloa (5). Ramón Domínguez Sánchez (6). Cándido Masa (7)].

\section{La enseñanza de la Microbiología en la Facultad de Medicina Santiago de Compostela (1933-1935)}

Una docencia regular de microbiología no se dio en Santiago hasta entrados los años 30. A diferencia de la Fisiología, que desde el Plan Moyano ya fue oficial como asignatura fundamental en los planes de estudios de las facultades de medicina españolas, la microbiología tuvo una presencia más tardía. En 1902, al mismo tiempo que se creaban nuevas disciplinas clínico-quirúrgicas -Oftalmología, Dermatología y Sifilografía y Enfermedades de Oídos, Nariz y Laringe- se modificó la tradicional Elementos de Higiene Pública, también presente desde 1857, para transformarse en Higiene con Prácticas de Microbiología Sanitaria,

pág. 3 y el núm. 17, 5708 (19 de noviembre de 1941), pág. 3-notificaron su presencia, al igual que el Boletín de la Universidad de Santiago de Compostela en el artículo titulado "El Profesor Hoffmann en la Facultad de Medicina", 10, 34 (1941), pág. 114. A instancias de Novo Campelo, decano de Medicina, se solicitó de la Junta de Gobierno que Hoffmann fuera nombrado profesor honorario de la Universidad compostelana. 
que en 1928, el año en que Guy vino a Santiago, pasó a llamarse Microbiología Médica. Con independencia de la ausencia de estudios monográficos dedicados al curso histórico de la microbiología e higiene en Santiago, sin embargo podemos apuntar algunos datos.

Es cierto que Varela de la Iglesia se sintió atraído a finales del siglo XIX por el estudio de las enfermedades infecciosas, como el tifus, el cólera y la sífilis. Además, hizo una estancia en París en (1886) para estudiar la vacuna antirrábica de Pasteur. Este interés hace concluir a Gurriarán y González Guitián que Varela fue el introductor de la microbiología en la Universidad de Santiago ${ }^{41}$.

En el cambio de siglo se dieron algunas pruebas del creciente interés de ciertos entornos compostelanos por la naciente microbiología, aunque no tanto en la propia Facultad de Medicina. El 3 de diciembre de 1900 el Eco de Santiago notificaba que el padre Plácido Rey Lemos había impartido una conferencia en El Ateneo en la que defendió la existencia de los microbios y rechazó la doctrina de la generación espontánea ${ }^{42}$. De mayor interés es la actividad llevada a cabo por el Instituto Pedreira, que estuvo activo por lo menos entre 1900 y 1916 . Tal Instituto fue fundado por el ferrolano Ángel Pedreira Labadía (n. 1864), un licenciado en medicina por Santiago que se doctoró en Madrid con una tesis sobre la microbiología y clínica de la difteria. Carente Medicina de una infraestructura idónea para la enseñanza y cultivo de esta ciencia, Pedreira le ofreció su Instituto como un centro asociado a la misma, ofrecimiento que cristalizó a comienzos de $1901^{43}$.

Desde esa fecha y hasta 1929, en que Vicente Goyanes Cedrón (1865-1954), catedrático de Histología y Anatomía Patológica, realice alguna activad formativa en Microbiología, esta disciplina apenas tuvo un desarrollo en la Facultad de Medicina de Santiago ${ }^{44}$. En 1931, por ejemplo, Goyanes Cedrón publicó un breve manual de Prácticas de Laboratorio para la "Clase de Microbiología Médica"45.

La situación cambió radicalmente en 1933 cuando Emilio Zapatero Ballesteros (1897-1987), pucelano de origen, licenciado en 1922 y doctor en 1932, accede a la cátedra compostelana de Higiene, que ocupará hasta 1935, en que regresó a

\footnotetext{
${ }^{41}$ R. Gurriarán, Ciencia ..., pág. 289; Carlos González Guití́n, Bibliografía médica gallega del siglo XIX, Universitat de València, Servei de Publicacions, 2008.

42 , núm. 1781 , pág. 2

${ }^{43}$ Rafael Sisto Edreira, "Ángel Pedreira Labadía”, en Álbum da Ciencia. Culturagalega.org. [en línea], disponible en $<$ http://www.culturagalega.org/albumdaciencia/detalle.php?id=298 $>$ [Consultado: 07/03/2015].

${ }^{44}$ En el curso 1916-1917 Goyanes se hizo con la enseñanza de esta materia (AHUS, Legajo 591, Expediente 10, y Expediente docente de Don Vicente Goyanes Cedrón).

${ }^{45}$ Durante el curso 1926-1927 Pena Pérez figuró como responsable de Higiene (El Compostelano, 7, 1963 (1926), pág. 3). Residencia de Estudiantes, Archivo de la JAE [en línea], disponible en $<$ http://archivojae.edaddeplata.org/jae_app/>, Expediente JAE/15-317.
} 
Valladolid. Siendo catedrático en Santiago consiguió en 1933 una pensión de la JAE por seis meses para trabajar en el Instituto de Higiene de la Universidad de Roma, junto a Giuseppe Sanarelli (1864-1940), y tras serle concedida prórroga en 1934 siguió sus estudios en el Institut Pasteur de París por tres meses más ${ }^{46}$. Apenas instalado en Santiago, Zapatero solicitó una reforma del laboratorio de Higiene y una subvención económica para la compra de medios para la enseñanza y la investigación ${ }^{47}$. En abril de 1935 la prensa local informaba de la reciente inauguración del Instituto de Higiene y Microbiología, al que la revista madrileña España Médica dedicaba un amplio reportaje en mayo de ese mismo año. Según Marial, el autor del informe, el Instituto disponía de una amplia Sala de Prácticas (24 puestos de trabajo) y un Departamento de Investigación con tres secciones: Química aplicada a la Higiene, Bacteriología y una tercera de Microfotografía, con una cámara oscura. El Instituto contaba con biblioteca propia, con las mejores revistas internacionales y las publicaciones de la Sección de Higiene de la Sociedad de Naciones. Además de la labor docente, el Instituto cumplía otros fines, foco de investigación y laboratorio al servicio de las clínicas del Hospital ${ }^{48}$. La permanencia de Zapatero en Santiago fue breve, aunque como hemos mostrado en el par de años en que estuvo desplegó una gran actividad. Tras su partida, vino por traslado desde Cádiz Ulpiano Villanueva.

Ulpiano Villanueva Castro (1900-1967), coruñés de Pontedeume, se licenció en Medicina en Santiago y en septiembre de 1926 se examinó del grado en medicina. Se doctoró en abril de 1932 en la Universidad Central con una memoria acerca del estudio del ph gástrico. En 1933, gracias a una beca de la Facultad de Medicina, realizó una estancia formativa en París, en el Institut Pasteur, con Guy y otros miembros del mismo, y a fines de ese año conseguía una ayuda de la Universidad compostelana para trabajar en Hamburgo en el IETNH, una estancia que se prolongó hasta enero de 1934. Por dos ocasiones, marzo de 1934 y febrero de 1935, solicitó una pensión a la JAE, sin éxito. En enero de 1935 conseguía la cátedra de Higiene y Microbiología de Cádiz, y apenas Zapatero dejó Santiago, Villanueva Castro pasó a ocupar la plaza vacante. El 10 de octubre de 1935 impartía su primera lección como catedrático en Santiago ${ }^{49}$.

\footnotetext{
${ }^{46}$ Residencia De Estudiantes, Archivo de la JAE [en línea], disponible en $<$ http://archivojae.edaddeplata.org/jae_app/>, Expediente Personal JAE/153-17. Previamente solicitó pensión para trabajar en el Institut Pasteur de París (1931 y 1932).

${ }^{47}$ R. Gurriarán, Ciencia..., pág. 420.

${ }^{48}$ Marial, "En la Facultad de Medicina de Santiago. Sección de Higiene y Bacteriología", España Médica, 26 (1935), págs. 12-14.

${ }^{49}$ Residencia De Estudiantes, Archivo de la JAE [en línea], disponible en $<\mathrm{http}: / /$ archivojae.edaddeplata.org/jae_app/>, Expediente Personal JAE/150-294. Ricardo GuRRIARÁN, Ciencia ..., págs. 422423; Antonio Rodríguez Cadarso, "Figuras de la Universidad Compostelana. 8. Ulpiano Villanueva Castro: Internista", El Correo Gallego, (9 de junio de 1985).
} 
En los escasos trabajos biográficos que hemos podido consultar no se ha recalcado suficientemente la labor como microbiólogo e higienista de Villanueva durante estos años, aunque sí su posterior dedicación y prestigio científico como internista. Durante su primera etapa compostelana Villanueva fue profesor Auxiliar y tuvo por encargo del decanato la docencia de varias asignaturas, por hallarse vacantes o porque el titular -tal fue en 1934 con García-Blanco- se hallaba ausente. De la de Higiene y Microbiología también se responsabilizó en algún curso académico. Como resultas de su estancia en Hamburgo publicó varios trabajos en prestigiosas revistas alemanas. Con anterioridad, durante las Jornadas Medicas Gallegas de Vigo de 1931, presentó tres comunicaciones, sobre la serología de la lepra, sobre la reacción de Wassermann y una tercera acerca del ph gástrico, muy probablemente un resumen de su memoria de doctorado.

Villanueva coincidió con Reichenow cuando este se hallaba en Santiago para impartir su curso de Parasitología, pues recién obtenida la cátedra de Cádiz, amigos y compañeros de Santiago le ofrecieron el 25 de marzo un banquete para celebrar su triunfo. A través de dos artículos aparecidos en El Pueblo Gallego en ese mismo mes, Villanueva ofreció una información de primera mano sobre el Instituto de Hamburgo y acerca de los recursos y personal que en él trabajaba. En uno de ellos, de forma inteligente, Villanueva apuntaba claramente que el Instituto de Hamburgo era, desde su fundación, uno de los arietes de la política científica de Alemania para su expansión en los países latinos y en Suramérica, pues personalmente pudo constatar la gran presencia de profesionales venidos de esas áreas geográficas para formarse en ese centro germano ${ }^{50}$.

De este breve resumen biográfico se concluye que Villanueva se esforzó desde que cursaba los estudios de medicina por recibir una sólida formación en ciencias básicas y experimentales. Recordemos que fue uno de los alumnos ayudantes de Hoffmann en el curso de 1923, que participó en el de 1924 y en el de Guy de 1928, que estuvo becado en París (1933) y en el IETNH de Hamburgo (1933). Es decir, Villanueva aspiraba a seguir una carrera docente en ciencias básicas médicas. Alcanzó el máximo reconocimiento en 1935 cuando consiguió la cátedra de Higiene y Microbiología, pero se centró por el resto de su vida en la medicina interna, especialmente en las enfermedades infecciosas.

\section{El curso de Técnica Microbiológica de Amédée Guy (1928)}

Cuatro años después de la segunda estancia de Hoffmann, en marzo de 1928 la Facultad de medicina concertó con el bacteriólogo francés Amédée Guy (1882-1957) su venida para impartir un curso de técnica microbiológica. En esta

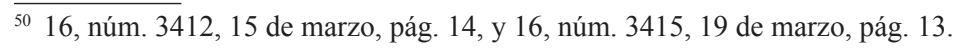




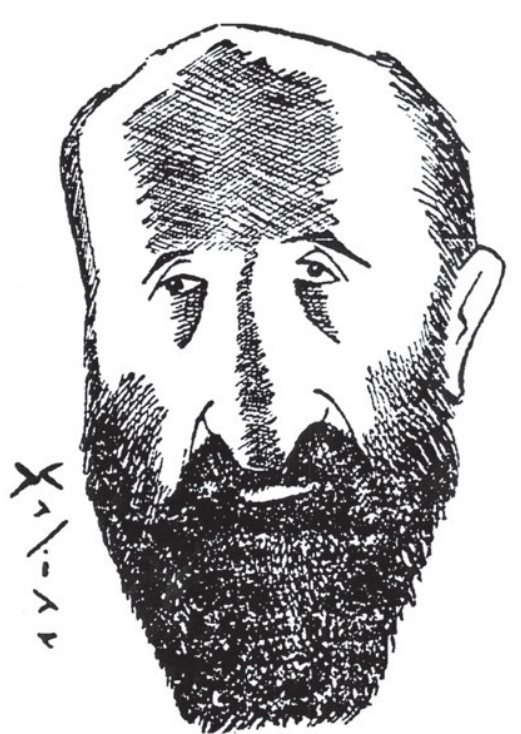

Figura 5. Amédée Guy (1882-1957).

Retrato de Carlos Maside publicado en El Pueblo Gallego de Vigo, el 12 de mayo de 1928.

ocasión debió pesar la opinión de Goyanes Cedrón, pues era el único claustral de medicina que había tenido previamente un aprendizaje con $\mathrm{Guy}^{51}$. Formado en ciencias físicas y naturales y medicina en La Sorbona, y en química y bacteriología en el Institut Pasteur, Guy era el Jefe del laboratorio del Hospice des Enfants Assistés y del Institut de Puericulture de París ${ }^{52}$. También estuvo asociado al Instituto del Cáncer de la Facultad de Medicina parisina, del que llegó a ser director.

A partir de 1935 Guy entró de lleno en la política, siendo Diputado por el Partido Socialista entre 1936 y 1942 y senador tras la Guerra (1946-1948). Fue uno de los 80 diputados y senadores que se opusieron en 1940 a la renuncia de sus actas parlamentarias a fin de conceder plenos poderes al mariscal Pétain ${ }^{53}$.

Como en el curso de Hoffmann, la Facultad acordó nombrar a diez alumnos de Medicina y Farmacia para que ejercieran de Ayudantes en la parte práctica del curso, que duró desde el 13 de abril hasta mediados de mayo ${ }^{54}$. Una vez de regreso a París, el superior de Guy en la Facultad de Medicina, André Lemierre (1875-1956), envió el 6 de junio una carta

\footnotetext{
${ }^{51}$ Goyanes estuvo en París aprendiendo bacteriología con Guy tras terminar sus estudios médicos. Guy era además el encargado de organizar los cursos de perfeccionamiento en dicha rama médica para doctores nacionales y extranjeros. Finalmente, cuando Guy impartió su primera conferencia en Santiago, Goyanes Cedrón la leyó en castellano, lo que evidencia el poco conocimiento idiomático de los alumnos de esa época. La relación de Goyanes Cedrón con Guy en: Juan José FernÁndez Teijeiro, Ramón Varela ..., pág. 43; Véase, además: Rafael Sisto EdreirA, "Vicente Goyanes Cedrón", en Álbum da Ciencia. Culturagalega.org. [en línea], disponible en <http://www.culturagalega.org/ albumdaciencia/detalle.php?id=378> [Consultado: 25/01/2015], y Gran Enciclopedia Gallega, Santiago-Gijón, Silverio Cañada editor, 1981, vol. XVI, pág. 177.

52 "Noticias". Revista Médica Gallega, 8 (4), pág. 127 (1928).

${ }^{53}$ Datos biográficos de Amédée Guy en: SÉNAT [en línea], disponible en <http://www.senat.fr/senateur-4eme-republique/guy_amedee0533r4.html\#1889-1940> [Consultado: 3/03/2015].

${ }^{54}$ Noticias de la estancia de Guy en Santiago, en la prensa local de ese año: El Compostelano, 9 (1928), núm. 2421, 13 de abril, pág. 3; 9 (1928), núm. 2423, 16 de abril, pág. 3; 9 (1928), núm. 2426, 19 de abril, pág. 3; 9 (1928), núm. 2431, 25 de abril, pág. 3; 9 (1928), núm. 2433, 27 de abril, pág. 1; El Pueblo Gallego, 5 (1928), núm. 1298, 14 de abril, pág. 1. No hemos podido identificar a los alumnos ayudantes del curso de Guy.
} 
a Piñeiro Pérez agradeciéndole las atenciones tenidas con Guy y, como en el caso de Hoffmann, le invitaba a que profesores y alumnos de Compostela se trasladaran Francia para ampliar estudios, pues siempre serían bien recibidos ${ }^{55}$. Además de varias noticias en la prensa local, nos queda un testimonio gráfico de Guy, rodeado de los alumnos del curso y de Goyanes y Villanueva, en una fotografía que publicó El Pueblo Gallego de Vigo el 15 de mayo, pero que no la hemos reproducido en este trabajo por su escasa calidad ${ }^{56}$.

\section{El Curso de Parasitología de Eduard REICHENOW (1935)}

El último cursillista fue el berlinés Eduard Reichenow (1883-1960), una autoridad mundial en parasitología, que di-

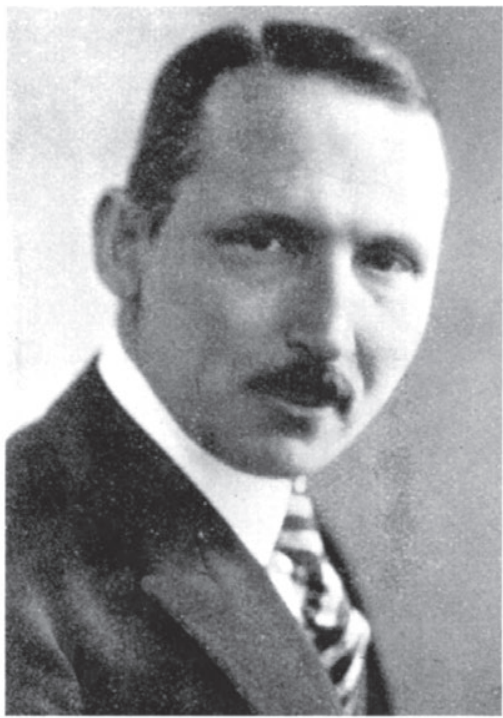

Figura 6. Eduard Reichenow (1883-1960) (En: G. OLpP, Hervorragende Tropenärzte in Wort und Bild, München, Otto Gmelin, 1932, Tafel LV). rigía la sección de Protozoos en el IETNH de Hamburgo. Formado en las universidades de Berlín, Heidelberg y Munich, Reichenow se graduó en ciencias naturales. Desde su etapa de estudiante se asoció al Instituto de Hamburgo y en el mismo desarrolló toda su vida académica, alcanzando con el tiempo la presidencia del mismo. Por razones de su trabajo estuvo desde fechas muy tempranas vinculado a España. Fue Socio de Número de la Real Sociedad Española de Historia Natural (1917) y en su revista publicó varios trabajos. Tras varios años en nuestro país asociado al Museo Nacional de Ciencias Naturales, apoyado por la JAE, regresó a Alemania en torno a 1920, aunque siguió manteniendo relaciones con esa institución española. En enero de 1932 era nombrado, avalado por Ignacio Bolívar y Pío del Río Hortega, entre otros, Socio Correspondiente de la Sociedad Española de Historia Natural ${ }^{57}$. En

\footnotetext{
${ }_{55}$ El Compostelano, 9 (1928), núm. 2474, 18 de junio, pág. 1. André Alfred Lemierre (1875-1956), era un reputado bacteriólogo y clínico, que ejercía en el Hôpital Bichat de París. Algunas de sus publicaciones están cofirmadas con Guy (André Lemierre, Titres et travaux scientifiques du Dr..., Paris, Masson et Cie, 1926).

${ }_{56}^{56}$ El Pueblo Gallego, 5 (1928), núm. 1322, 15 de mayo, pág. 16.

57 "Sesión Extraordinaria de 13 de enero de 1932", Boletín de la Sociedad Española de Historia Natural, 32 (1932), págs. 71-72.
} 
1957 fue nombrado, a propuesta de la Facultad de Farmacia, doctor honoris causa por la Universidad de Granada ${ }^{58}$.

De la presencia de Reichenow en Santiago en 1935 tuvieron que ver mucho Zapatero y Villanueva Castro, pues como acabamos de comentar Zapatero era el catedrático de la disciplina y Villanueva ya había trabado relación con Reichenow a raíz de su estancia en el Instituto de Hamburgo en el último semestre de 1933.

El curso de Reichenow coincidió con la inauguración del Instituto de Higiene y Microbiología, puesto en marcha por Zapatero Ballesteros, y con un ciclo de conferencias de Extensión Universitaria organizado por el propio Zapatero, que incluyó en el mismo, con carácter especial, el curso de Reichenow.

La asignatura de Reichenow se prolongó por dos semanas, última de marzo y primera de abril. Como en otros cursos, además de conferencias -una de ellas sobre "El origen y desarrollo del parasitismo de los protozoos y las adaptaciones de los parásitos"59- el componente práctico jugó el papel principal. Los 24 alumnos inscritos acudían todas las tardes, de cuatro a ocho, al laboratorio de Higiene para reconocer y estudiar, auxiliados por Reichenow, parásitos y otros agentes causantes de enfermedades en el hombre. Una espléndida colección de diapositivas facilitaba el aprendizaje. Para enriquecer los materiales de la cátedra Reichenow donó a la misma un lote de sus preparaciones ${ }^{60}$. Otra novedad que introdujo Reichenow fue la proyección de películas. El día 4 de abril se exhibió "Instituto de Enfermedades Tropicales y Navales de Hamburgo" y al día siguiente, con motivo de su despedida, mostró nuevas películas relacionadas con el Instituto ${ }^{61}$. Desde Santiago Reichenow marchó a Madrid para nuevamente impartir conferencias en el Instituto Nacional de Sanidad y asistir al Congreso Internacional de Entomología, a celebrar a partir de septiembre, bajo la presidencia de Ignacio Bolívar, máxima autoridad del Museo Nacional de Ciencias Naturales.

Santiago fue también sensible a la presencia en sus aulas de prestigiosos profesionales extranjeros como conferenciantes. Tal es el caso de Hermann Krukenberg (1863-1935), un reconocido traumatólogo alemán que vino a España en 1923

\footnotetext{
${ }_{58}$ P. C. C. Garnham, "Prof. Eduard Reichenow”, Nature, 187 (1960), págs. 554-555; A. Hase, "Professor Dr. Phil. Dr. h. c. Eduard Reichenow zum Gedächtnis", Zeitschrift für Parasitenkunde, 20 (1960), págs. 135-137. G. OLpP, Hervorragende Tropenärzte in Wort und Bild, München, Otto Gmelin, 1932, págs. 341-342. Con toda seguridad el doctorado de Granada fue promovido por Carlos Rodríguez López-Neyra de Gorgot (1885-1958), catedrático de Parasitología en esa Facultad, y una autoridad mundial en esa materia.

${ }^{59}$ Una amplia crónica de la misma en E. BALADRÓN, "Espléndida conferencia del profesor alemán Reichenow en el Teatro Principal”, El Pueblo Gallego, 12 (1935), núm. 3427, 2 de abril, pág. 13.

${ }^{60}$ Emilio Zapatero, "El cursillo de Parasitología del profesor Reichenow", El Pueblo Gallego, 12 (1935), núm. 3424, 29 de marzo, pág. 10.

61 “El Doctor Reichenow”, El Pueblo Gallego, 12 (1935), núm. 3429, 4 de abril, pág. 11.
} 
invitado por el Cuerpo de Sanidad Militar ${ }^{62}$. En Madrid habló en la Facultad de Medicina del "Tratamiento quirúrgico de la escoliosis" (21 de noviembre), en el Instituto Rubio acerca de "Mi procedimiento de cineplastia en los amputados de antebrazo" (22 de noviembre), en la Residencia de Estudiantes sobre "La expresión del rostro humano" (3 de diciembre) y en la Biblioteca del Instituto de Higiene sobre sus métodos de mejora de los amputados (6 de diciembre) ${ }^{63}$. En Santiago recaló a fines de ese año. Su estancia fue corta, pues impartió sólo tres charlas en la Facultad de medicina a partir del 15 de diciembre, en parte una repetición de las dadas en Madrid. Concretamente, "Sobre el tratamiento de la escoliosis", "Sobre mi procedimiento de cineplastia en los amputados de antebrazo" y "Sobre el tratamiento del pie plano y del pie zambo" ${ }^{\prime 4}$.

\section{Conclusiones}

Frente a una "retórica de la excelencia", fomentada secularmente en Santiago por la propia Universidad y por los medios de comunicación locales, especialmente la prensa diaria, que tendieron a idealizar una "Escuela Médica Compostelana" inexistente, dada la diversidad de intereses de los docentes de la facultad de Santia-

\footnotetext{
$\overline{{ }^{2} 2}$ Formado en Bonn, Heidelberg y Estrasburgo, Krukenberg fue inicialmente ayudante de Friedrich Trendelenburg en Bonn y de Max Schede en el hospital Eppendorf de Hamburgo. Durante la I Guerra Mundial fue cirujano de campo, lo que le permitió adquirir una gran experiencia en cirugía traumatológica. En 1917 ideó una técnica quirúrgica, conocida como "método Krukenberg", o cineplastia, para los amputados de una o de las dos manos, que consiste en crear una especie de pinza artificial a partir de la separación del cúbito y del radio. En 1907 fundó una clínica privada en Elberfeld (Markwart MichleR, "Krukenberg, Hermann”, Neue Deutsche Biographie, vol. 13, 1982, pág. 119, Deutsche Biographie [en línea], disponible en: $<$ http://www.deutsche-biographie.de/pnd102723842. html $>$ [Consultado: 4/03/2015]. Desechada por antiestética su técnica, sin embargo en los últimos años se ha vuelto a usar en los amputados simples y dobles de las guerras civiles africanas, especialmente en Sierra Leona (François Irmay, B. Merzouga y D. Vettorel, "The Krukenberg procedure: a surgical option for the treatment of double hand amputees in Sierra Leone", Lancet, 2 (2000), págs. 1072-1075).

${ }^{63}$ Una de las primeras noticias sobre la cineplastia de Krukenberg procede del cirujano militar Manuel Bastos Ansart (1887-1973) en una conferencia que impartió en el Ateneo de Alumnos Internos de la Facultad de Medicina de Madrid el 26 de abril de ese año ( $L a$ Voz, 4 (1923), núm. 884, 27 de abril, pág. 4). Toda la información de que disponemos apunta a que fue Bastos, precisamente, quien invitó a Krukenberg a dar el ciclo de charlas de Madrid (Manuel BAStos ANSART, De las guerras coloniales a la Guerra Civil. Memorias de un cirujano, Barcelona, Ediciones Ariel, 1969, págs. 170171). Cuando Krukenberg llegó a Madrid visitó en noviembre, acompañado de Bastos, el Instituto de Reeducación de Inválidos del Trabajo y aprovechó para operar con su técnica a varios de los ingresados (El Sol, 7 (1923), núm. 1957, 17 de noviembre, pág. 8).

64 "El Profesor Krukenberg en Santiago", Revista Médica Gallega, 3 (1923), pág. 353. Las conferencias fueron publicadas en Revista Médica Gallega en 1924, con un rico aparato iconográfico. La charla sobre el pie plano y zambo la publicó primero, sin iconografía, la Revista Íbero-Americana de Ciencias Médicas, 50 (1923), págs. 241-251.
} 


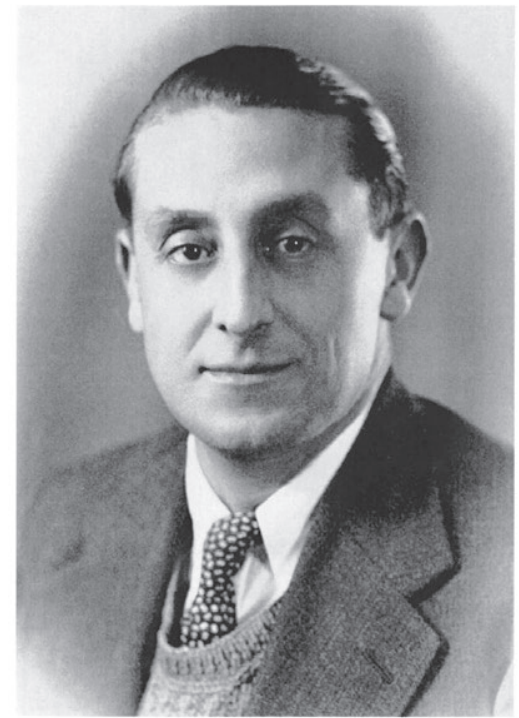

Figura 7. José María García-Blanco Oyárzabal (1898-1973).

go y la ausencia de un programa común de trabajo, así como la escasez de medios y de dotaciones, especialmente en las disciplinas más experimentales, las iniciativas de los decanos Piñeiro Pérez y Novo Campelo por traer profesores extranjeros -como docentes, Hoffmann, Guy y Reichenow, o bien conferenciantes, como Krukenbergevidenciaron las carencias de la Facultad y paliaron momentáneamente el bajo nivel formativo que recibían los alumnos en esas materias ${ }^{65}$.

Conviene recordar que en Fisiología, tras Varela de la Iglesia, no hubo otro catedrático de esta disciplina hasta 1927, año en que García-Blanco Oyarzábal, un magnífico bioquímico formado con Juan Negrín López (1892-1956), la desempeñó hasta $1934^{66}$. Precisamente ese año, el último de la estancia de García-Blanco en Santiago, la revista España Médica publicaba en su número de mayo un amplio reportaje acerca del recientemente creado Instituto de Farmacología y Fisiología Experimental, que dirigían Novo Campelo y García-Blanco. Por la información que ofrece Raviul, el autor del artículo, el Instituto estaba espléndidamente dotado, especialmente en su sección de fisiología y bioquímica, pues disponía además de una biblioteca especializada, de un quirófano para experimentación animal ${ }^{67}$.

No cabe duda que el esfuerzo de la Facultad por dotarse de un laboratorio adecuado al objeto de que Hoffmann pudiera llevar a cabo sus cursos con dignidad, fue un acicate que supo aprovechar García-Blanco cuando en 1927 llegó a

\footnotetext{
${ }^{65}$ En febrero de 1931, por ejemplo, una solicitud de la Asociación Profesional de estudiantes de Medicina para que los catedráticos y profesores auxiliares dieran cursos formativos complementarios tuvo una respuesta desigual por parte éstos. Se comprometieron a colaborar seis, nueve declinaron la invitación y otros seis no habían respondido todavía a la demanda. Entre los favorables estaban Ulpiano Villanueva (Higiene), Ramiro Sánchez Calvo (Fisiología) y Luciano Sánchez Guisande (Bacteriología) (El Pueblo Gallego, 8 (1931), núm. 2150, 24 de febrero, pág. 1).

${ }^{66}$ B. J. M. Hernández Iranzo, José María García-Blanco....

${ }^{67}$ Raviul, "Facultad de Medicina de Sarbiar (sic). Instituto de Farmacología y Fisiología Experimental", España Médica, 25 (1934), págs. 27-29. Probablemente se trate de Ramón Villarino Ulloa (1907-1990), profesor auxiliar temporal de Farmacología Experimental y Terapéutica Clínica, que en 1936 publicó en la revista viguesa RAIG con el mismo acrónimo un artículo de igual título.
} 
Santiago, una instalación que reforzó en 1934 con la creación del citado Instituto de Farmacología y Fisiología Experimental.

Algo parecido podemos resumir en relación con la Microbiología e Higiene, pues hasta la presencia de Zapatero Ballesteros (1933-1934) y Villanueva Castro (1935), la enseñanza de esta disciplina dependió de iniciativas personales de otros docentes, como Goyanes Cedrón. Es llamativo que en 1918 el único artículo riguroso aparecido en la prensa diaria gallega sobre la epidemia de gripe reinante fuera de Gustavo Pittaluga (1876-1956), catedrático de Parasitología en la Universidad Central ${ }^{68}$.

De todos los científicos alemanes que vinieron a España en esos años, quizás el único que estuvo en condiciones semejantes a los estudiados para el caso de Santiago fue el vienés Richard Adolf Zsigmondy (1865-1929), que en 1922 expuso dos cursos sobre química, uno en Zaragoza, por expresa invitación de Antonio de Gregorio Rocasolano (1873-1941), catedrático de química general, a fines de octubre, y el segundo en Valencia (octubre/noviembre). Sin embargo la estancia Zsigmondy, que sería galardonado con el premio Nobel de Química en $1925^{69}$, tuvo algunos matices diferentes a las de Hoffmann y Guy, aunque más próximo en duración al de Reichenow. Primeramente, Zsigmondy fue un conferenciante relativamente efímero tanto en Zaragoza como en Valencia (dos semanas, aproximadamente entre ambas ciudades) mientras que las dos primeras estancias de Hoffmann se demoraron en total por cuatro meses y medio, y la tercera prácticamente por uno, al igual que la de Guy ${ }^{70}$. Otra diferencia es que, como ya señalamos, Hoffmann fue contratado por la Universidad -lo que no sucedió con Zsigmondy-y, que nosotros sepamos, la participación en las actividades prácticas por los estudiantes gallegos fue gratuita, al igual que la asistencia a las conferencias. Finalmente, la Facultad de Medicina de Santiago hizo de la venida de Hoffmann un acontecimiento de primer orden en su vida académica. Recordemos las profundas reformas estructurales y la compra de material científico para que Hoffmann pudiera dar sus clases en óptimas condiciones.

Como ya dijimos Hoffmann, Guy y Reichenow se mostraron abiertos a que profesores y estudiantes compostelanos marcharan a sus respectivos centros para ampliar conocimientos. Esta invitación se plasmó en varias estancias, aunque alguna de ellas fue incluso previa a sus visitas a Santiago.

\footnotetext{
68 “Opinión del Sr. Pittaluga”, El Eco de Santiago, 23 (1918), núm. 10.023, 17 de octubre, pág. 1.

${ }^{69}$ Una síntesis biográfica de Zsigmondy en NobelpRIze.Org [en línea], <http://www.nobelprize.org/ nobel_prizes/chemistry/laureates/1925/zsigmondy-bio.html> [Consultado: 4/03/2015].

${ }^{70}$ Muy certeramente señalaba El Eco de Santiago en enero de ese año que la presencia de Hoffmann en Santiago sería de más calado y cualitativamente diferente a otras estancias de profesores extranjeros en España, básicamente por las condiciones de su venida y por larga duración del curso que iba a dar El Eco de Santiago (1923), núm. 11.359, 9 de enero, pág. 2).
} 
Ulpiano Villanueva, por ejemplo, catedrático en Cádiz, en febrero de 1935 solicitó de la JAE una pensión para trabajar en el Instituto de Reichenow, que no se le concedió, pero en la instancia de solicitud manifestaba que ya había estado en dicho centro con anterioridad, a finales de 1933, por un periodo de cuatros meses, como ya señalamos ${ }^{71}$. José Carlos Colmeiro Laforet, licenciado en medicina por Santiago en 1928, fue becado por el Patronato de su Universidad para trabajar con Hoffman el mismo año de conclusión de sus estudios de medicina, entre noviembre de 1928 y marzo del siguiente año. Aunque solicitó pensión de la JAE para proseguir sus trabajos en Alemania, no parece ser que se le concediera $^{72}$. El año de la segunda visita de Hoffmann a Santiago Germán Caamaño hizo una estancia formativa con Friedrich Holtz, el bioquímico que le acompañó en este segundo viaje ${ }^{73}$.

Fuera del ámbito universitario hay que mencionar la estancia en fecha no determinada de Luis Sieyro Nieto, quizás becario del Patronato de la Universidad de Santiago, con Hoffmann ${ }^{74}$, y la de Román Pereiro Cuesta con Guy. En marzo de 1929 El Pueblo Gallego de Vigo publicaba la noticia de que Román Pereiro, médico, formado en el Instituto Pasteur de París con Guy, se hacía cargo de la dirección del laboratorio de análisis clínicos de su hermano Pablo, farmacéutico, recientemente fallecido. Entendemos que recalcar en la noticia esa relación de Román Pereiro con Guy era una prueba de su sólida formación y que, por tanto, su labor como analista gozaba de las mejores garantías científicas ${ }^{75}$.

\section{BibLIOGRAFÍA}

Barcia Goyanes, Juan José, La saga de los Barcia, Valencia, Artes Gráficas Soler, 2003.

Barcia Goyanes, Juan Luis, Fisiología Experimental. Memoria-Resumen de los trabajos realizados por el Pr. P. Hoffmann en la Facultad de Medicina, durante los meses de Marzo, Abril y Mayo del Curso 1923, Santiago, Tipografía "La Comercial”, 1926.

Barral Martínez, Margarita, "O mecenado de Montero Ríos na Universidade de Santiago", Semata, 10 (2008), págs. 222-225.

Bastos Ansart, Manuel, De las guerras coloniales a la Guerra Civil. Memorias de un cirujano, Barcelona, Ediciones Ariel, 1969.

\footnotetext{
${ }^{71}$ Residencia De Estudiantes, Archivo de la JAE [en línea], disponible en $<$ http://archivojae.edaddeplata.org/jae_app/>, Expediente Personal, JAE/150-294.

${ }^{72}$ Residencia de Estudiantes, Archivo de la JAE [en línea], disponible en $<$ http://archivojae.edaddeplata.org/jae_app/>, Expediente Personal JAE/37-574. Más noticias sobre Colmeiro en R. GURRIARÁN, Ciencia..., págs. 374-375.

${ }^{73}$ AHUS, Expediente docente del Prof. D. Germán Caamaño Solar.

74 "Un aventajado alumno más de la Escuela Médica Gallega", RAIG (1936), núm. 13, pág. 10.

75 "El Laboratorio de análisis clínicos de D. Pablo Pereiro", El Pueblo Gallego, 6 (1929), núm. 1585, 20 de marzo, pág. 6 .
} 
Bermejo Patiño, Manuel R. y Gurriarán, Ricardo, Rodríguez Cadarso. Un reitor para un país, Santiago de Compostela, Universidad, 2008.

Blasius, Wilhelm, "Zur Geschichte der Reflexlehre unter besonderer Würdigung des Beitrages von Paul Hoffmann”, Deutsche Zeitschrift für Nervenheilkunde, 186 (1965), págs. 475-495.

Capelán Rey, Antón, "Contribucións a unha historia da Universidade Popular da Coruña", Sarmiento, 3 (1999), págs. 25-64.

Bugallo, Ánxela, “Alejandro Rodríguez Cadarso”, en Álbum da Ciencia. Culturagalega.org. [en línea], disponible en $<$ http://www.culturagalega.org/albumdaciencia/detalle.php?id=255> [Consultado: 05/02/2015].

Cagiao Vila, Pilar y Rey Tristán, Eduardo, "La Biblioteca América de la Universidad de Santiago en su centenario (1904-2004)", Anuario Americanista Europeo, núm. 3 (2005), págs. 415-428.

Fernández Teijeiro, Juan José, Ramón Varela de la Iglesia (1845-1922). Positivismo e Histología en Fonseca, Tesis de Doctorado, Universidad de Santiago de Compostela, 2007, [en línea], disponible en $<\mathrm{http}: / /$ hdl.handle.net/10347/2364> [Consultado: 05/01/2015].

Garnham, P. C. C., "Prof. Eduard Reichenow”, Nature, 187 (1960), págs. 554-555.

Glick, Thomas F., Einstein y los españoles. Ciencia y sociedad en la España de entreguerras, Madrid, CSIC, 2005.

González Guitián, Carlos, Bibliografía médica gallega del siglo XIX, Universitat de València, Servei de Publicacions, 2008 [en línea], tesis doctoral disponible en $<$ http://roderic.uv.es/ bitstream/handle/10550/15196/guitian.pdf?sequence=1 $>$ [Consultado: 20/02/2015].

Granda Juesas, Juan Manuel, Don Misael Bañuelos. Medicina, antropología, sociedad, Valladolid, Secretariado de Publicaciones de la Universidad, 1987.

Gurriarán, Ricardo, Ciencia e conciencia na Universidade de Santiago (1900-1940). Do influxo institucionista e a JAE á depuración do profesorado, Santiago de Compostela, Servizo de Publicacións da Universidade de Santiago de Compostela, 2006.

Hase, A., "Professor Dr. Phil. Dr. h. c. Eduard Reichenow zum Gedächtnis", Zeitschrift für Parasitenkunde, 20 (1960), págs. 135-137.

Hera Martínez, Jesús de la, La política cultural de Alemania en España en el período de entreguerras, Madrid, CSIC, 2002.

Hernández Iranzo, Bernardo José María, José María García-Blanco Oyarzábal. "El hombre y su Obra”. Una etapa de la Bioquímica y de la Fisiología valenciana (1941-1968), València, Universitat-Servei de Publicacions, 2003.

Irmay, François; Merzouga, B. y Vettorel, D., "The Krukenberg procedure: a surgical option for the treatment of double hand amputees in Sierra Leone", The Lancet, 2 (2000), págs. 1072-1075.

Jung, Richard, "Paul Hoffmann 1884-1962", Reviews of Physiology, Biochemestry and Experimental Pharmacology, 61 (1969), págs. 1-17.

Lemierre, André, Titres et travaux scientifiques du Dr..., Paris, Masson et Cie, 1926.

Liñares Giraut, X. Amancio, "Gaveando no Agrarismo Barcalés: La Federación de Negreira y Baña (1911)", en Xesús Balboa López y Herminia Pernas Oroza (coords.), Entre nós. Estudios de Arte, Xeografía e Historia en Homenaxe ó Profesor Xosé Manuel Pose Antelo, Santiago de Compostela, Universidade-Servicio de Publicacions, 2011, págs. 867-876. 
López Piñero, José María, Diccionario de histórico de la ciencia moderna en España, 2 vols., Barcelona, Ediciones Península, 1983.

Marial, "En la Facultad de Medicina de Santiago. Sección de Higiene y Bacteriología”, España Médica, 26 (1935), págs. 12-14.

Michler, Markwart, “Krukenberg, Hermann”, Neue Deutsche Biographie, 13 (1982), pág. 119, DEUTSCHE BIOGRAPHIE [en línea], disponible en: < http://www.deutsche-biographie. de/pnd102723842.html> [Consultado: 4/03/2015].

Nauck, Ernst Georg, "50 Jahre Hamburger Tropeninstitut", Zeitschrift für Tropenmedizin und Parasitologie, 2 (1950), págs. 151-75.

Olagüe de Ros, Guillermo, "La Unión Médica Hispano-Americana (1900) y su contribución al internacionalismo científico", Dynamis, 26 (2006), págs. 151-168.

Olagüe de Ros Guillermo, "La colaboración hispano-latinoamericana en los orígenes y desarrollo del movimiento documental europeo contemporáneo (1900-1920)", Encontros Bibli: Revista Eletrônica de Biblioteconomia e Ciência da Iformaçao, núm. esp., $2^{\circ} \mathrm{sem}$., págs. 82-95, 2006 [en línea], disponible en $<$ https://periodicos.ufsc.br/index.php/eb/article/ view/1518-2924.2006v11nesp2p82/429> [Consultado: 26/06/2015].

Olagüe de Ros, Guillermo, "El internacionalismo científico de principios del siglo XX y su refuerzo de las ciencias nacionales", en Gregorio González Alcaide, Javier Gómez Ferri y Víctor Agulló Calatayud (eds.), La colaboración científica: una aproximación multidisciplinar, València, Nau Llibres, 2013, págs. 109-118.

Olpp, G., Hervorragende Tropenärzte in Wort und Bild, München, Otto Gmelin, 1932.

Ponte Hernando, Fernando; Pascual Bueno, José y González-Castroagudín, Sonia, “Juan José Barcia Goyanes", en Álbum da Ciencia. Culturagalega.org. [en línea], disponible en $<$ http:// www.culturagalega.org/albumdaciencia/detalle.php?id=499> [Consultado: 01/03/2016].

Raviul, "Facultad de Medicina de Sarbiar. Instituto de Farmacología y Fisiología Experimental”, España Médica, 25 (1934), págs. 27-29.

Rebok, Sandra (ed.), Traspasar fronteras: un siglo de intercambio cientifico entre España y Alemania. Über Grenzen hinaus: ein Jahrhundert deutsch-spanische Wissenschaftsbeziehungen, Madrid, CSIC, 2009.

Renaudet, Isabelle, "Diffusion des pratiques médicales et stratégies de promotion professionnelle à travers l'exemple de la Revue de l'Union médicale francoibéro-américaine (1912-1940)", El Argonauta español, 8 (2011), págs. 11-24, [en línea], disponible en $<$ http://argonauta. revues.org/169> [Consultado: 15/12/2014].

Sá, Magali Romero y Da Silva, André Felipe Cândido, "Por entre as páginas do imperialismo germânico na América Latina: a Revista Médica de Hamburgo e a Revista Médica Germano-Ibero-Americana (1920-1933)", Associação Nacional de História-ANPUH. XXIV Simpósio Nacional de História, 2007, [en línea], disponible en < http://www.snh2007. anpuh.org/> [Consultado: 14/01/2015].

Sá, Magali Romero y da Silva, André Felipe Cândido, "La Revista Médica de Hamburgo y la Revista Médica Germano-Ibero-Americana: diseminación de la medicina germánica en España y América Latina (1920-1933)", Asclepio, 62 (2010), págs. 7-34.

Sansone, Jason M.; Gatzke, Angela M.; Aslinia, Florence; Rolak, Loren A. y Yale, Steven H., "Jules Tinel (1879-1952) and Paul Hoffmann (1884-1962)", Clinical Medicine \& Research, 4 (2006), págs. 85-89. 
INTENTOS DE RENOVACIÓN DE ALGUNAS DISCIPLINAS EXPERIMENTALES EN LA

FACULTAD DE MEDICINA DE SANTIAGO: LOS CURSOS DE PAUL HOFFMANN

(1923 Y 1924), AMÉDÉE GUY (1928) Y EDUARD REICHENOW (1935)

Schroeder-Gudehus, Brigitte, Les scientifiques et la paix. La communauté scientifique internationale au cours des années 20, Montréal, Les Presses de l'Université de Montréal, 2014.

Simón Lorda, David, Locura, medicina, sociedad: Ourense (1875-1975), Ourense, Fundación “Cabaleiro Goás"-Complexo Hospitalario de Ourense, 2005.

Zimmer, Einz-Gerd, "The Heart-Lung Machine was Invented Twice -the first time by Max von Frey”, Clinical Cardiology, 26 (2003), págs. 443-445. 